\title{
The Identity Crisis of Hard Cider
}

\author{
Nicolas Fabien-Ouellet ${ }^{1} \&$ David Scott Conner ${ }^{2}$ \\ ${ }^{1}$ Food Systems Graduate Program, University of Vermont, USA \\ ${ }^{2}$ Department of Community Development and Applied Economics, University of Vermont, USA \\ Correspondence: Nicolas Fabien-Ouellet, Food Systems Graduate Program, University of Vermont, USA. E-mail: \\ nfabieno@uvm.edu
}

Received: December 5, 2017

Accepted: December 21, 2017

Online Published: February 11, 2018

doi:10.5539/jfr.v7n2p54

URL: https://doi.org/10.5539/jfr.v7n2p54

\begin{abstract}
In the past 5 years, the hard cider industry in the U.S. has undergone a sudden and dramatic growth period. This boom initially revealed challenges on the cider-specific apple supply side, but issues on the hard cider demand side have also emerged. This mixed methods study conducted in Vermont, a crucial player of the U.S. hard cider industry, addresses the gaps in the literature both on the apple supply side, and on the hard cider demand side. On the apple supply side, fourteen semi-structured interviews demonstrated that neither a long-term formalized contract nor a cooperative model (the two strategic partnership mechanisms used by world's leading industries to manage cider-specific apple production) are appropriate for the current Vermont industry context. On the hard cider demand side, cider makers expressed high interest in working under a geographical indication (GI) label to develop consumers' hard cider literacy and increase demand. This research further indicates that GIs can act as a powerful economic development tool. Introducing hard cider GIs could address current hard cider industry issues on both the supply side and the demand side.
\end{abstract}

Keywords: hard cider, geographical indications, strategic partnership, cider-specific apples, taste

\section{Introduction}

After years of exponential growth (Petrillo, 2016), the hard cider industry finds itself at a critical juncture. While the more mature European cider industries offer well-defined products, such as the "Herefordshire cider," the "cidre de Bretagne," or the "sidra de Asturias," the U.S. hard cider industry still offers products that oscillate between the borrowed identities of beer and wine, and lack clear and cohesive definitions. This malleable character prevents the U.S. hard cider industry from maturing, and makes it difficult for the industry to retain customers gained in the last few years, as well as attract new customers. The hard cider industry is aware of the issue. The number one goal in the 2017-2020 Strategic Plan for the United States Association of Cider Makers (2017) is to, "...grow demand for all styles of cider in the U.S. market." Additionally, the association would like to, "Establish a nationally-recognized consumer-focused cider lexicon with the explicit goal of helping consumers of differing cider knowledge identify cider styles and products they are most likely to enjoy." There are two layers of differentiation at play in this goal: (1) affirming American hard cider as a drink with its own identity, distinct from European cider; and (2) differentiating between the diverse hard cider styles within the U.S. industry.

According to Petrillo (2016), from 2011 and 2016, the hard cider industry has grown at an annualized rate of $27.3 \%$. This sudden and rapid growth has inspired researchers across producing states to study the challenges faced by the industry. So far, the literature on the topic has focused on the lack of supply of cider-specific apples in the U.S. domestic market. Virtually no research has been undertaken on the demand side of hard cider, with the exception of Tozer, Galinato, Ross, Miles, \& McCluskey (2015), who looked at the willingness to pay of consumers for specific profiles of hard cider.

This paper uses mixed methods to fill the gap in the literature on both the apple supply side and the hard cider demand side. On the apple supply side, this study uses semi-structured interviews conducted with industry stakeholders, primarily apple growers and cider makers, to explore the possibility of long-term formalized contracts or cooperatives to stimulate the production of cider-specific apples. On the hard cider demand side, a survey is used to gauge interest of cider makers in a geographical indication (GI) labeling system to differentiate between the different hard cider styles, potentially increasing demand. Overall, respondents emphasized that 
efforts surrounding the planting of additional cider-specific apple trees must be preceded by an increase in demand for hard ciders made with cider-specific apples. Vermont cider makers expressed the desire to source more cider-specific apples from their area, so this study focuses on the Vermont cider industry (Becot et al., 2016a). In the following literature review, we summarize the current state of the hard cider industry in the U.S. and Vermont. We also describe how the world's leading cider-specific apple industries manage their production, and explore how ciders are differentiated through GI certifications.

\section{Literature Review}

\subsection{What is Hard Cider?}

In the United States, cider is categorized as sweet - made of unfiltered apple juice - or hard - made from the fermentation of unfiltered apple juice (Petrillo, 2016). The apples used by U.S. cider makers today can be sourced from an array of apple cultivars, including lower-grade dessert cultivars (e.g. 'McIntosh', 'Cortland'), dual-purpose cultivars that can be grown for both the fresh or cider market (e.g. 'Idared', 'Northern Spy'), cider-specific apple cultivars like bittersharp (e.g. 'Kingston Black'), and bittersweet cultivars (e.g. 'Dabinett', Fillbarrel'). Cider-specific apples are apples with the unique flavors, high-acid qualities, and astringent tannin characteristics suited only to hard cider production (McGee, 2004).

In 2017, the Alcohol and Tobacco Tax and Trade Bureau (TBB), which regulates alcohol sales in the United States, classifies hard cider as a wine, and defines three tax classes of hard cider (Alcohol and Tobacco Tax and Trade Bureau [TBB], 2017a). An "artificially carbonated hard cider" is a hard cider that is artificially injected with carbon dioxide, and contains between 0.392 and 0.64 grams of carbon dioxide per 100 milliliters. A "still hard cider" is a hard cider that contains less than 0.392 grams of carbon dioxide per 100 milliliters. "Sparkling hard cider" refers to a hard cider that contains between 0.392 and 0.64 grams of carbon dioxide per 100 milliliters, and is the result of the secondary fermentation of the cider within a closed container. The TBB does not consider whether a hard cider is made with cider-specific fruits, dual-purpose cultivars, or with dessert cultivars.

\subsection{The Rise of the Hard Cider Industry}

While many areas of Europe have their own version of the drink that draws on heritages that are thousands of years old, the apple was only brought to the Americas a few centuries ago by European settlers. Watson (2013) documents how hard cider shaped the lives of American colonists in the Northeast from the $17^{\text {th }}$ to the $19^{\text {th }}$ century and quickly became the U.S. "national drink," as both adults and children, the elite and working-class people all consumed the fermented apple beverage.

As seen in Figure 1, in 1899, 55 million gallons ( 2 million hectolitres) of hard cider were produced in the United States. However, following the passage of the $18^{\text {th }}$ Amendment, production of hard cider decreased to 13 million gallons (492,000 hectolitres) in 1919. The drink was slowly abandoned in the $20^{\text {th }}$ century; in 1990 , only 271,000 gallons (10,000 hectolitres) were produced. Hard cider began to make a comeback in the 1990s, and in 1996, the production increased to 5.3 million gallons (200,600 hectolitres) (Watson, 2013).

By 2015, the TBB reported 55 million gallons (2 million hectolitres) produced in the United States (TBB, 2017b). This hard cider boom was in part attributed to the "craft beer" movement, which inspired consumers to experiment with new "craft beverages" (Petrillo, 2016). Watson (2013) further indicates that the hard cider comeback was largely driven by "...large national or multinational brands, whose owners have the capital and the distribution channels to get bottles (and now cans) of their product onto store shelves." In 2016, the production of hard cider went down to 47 million gallons (1.8 million hectolitres), and sales in the United States totaled \$209.7 million in revenue (TBB, 2017b; Petrillo, 2016). IBISWorld projects that the recent U.S. decline in hard cider production will level off toward long-term stability, with a $1.2 \%$ annualized growth rate in revenue over the next five years (Petrillo, 2016). Even after the dramatic increase in production seen in recent decades, Petrillo (2016) suggests that the hard cider industry is not mature yet; rather, it has passed the stage of quantity growth, and has entered the stage of quality growth. 


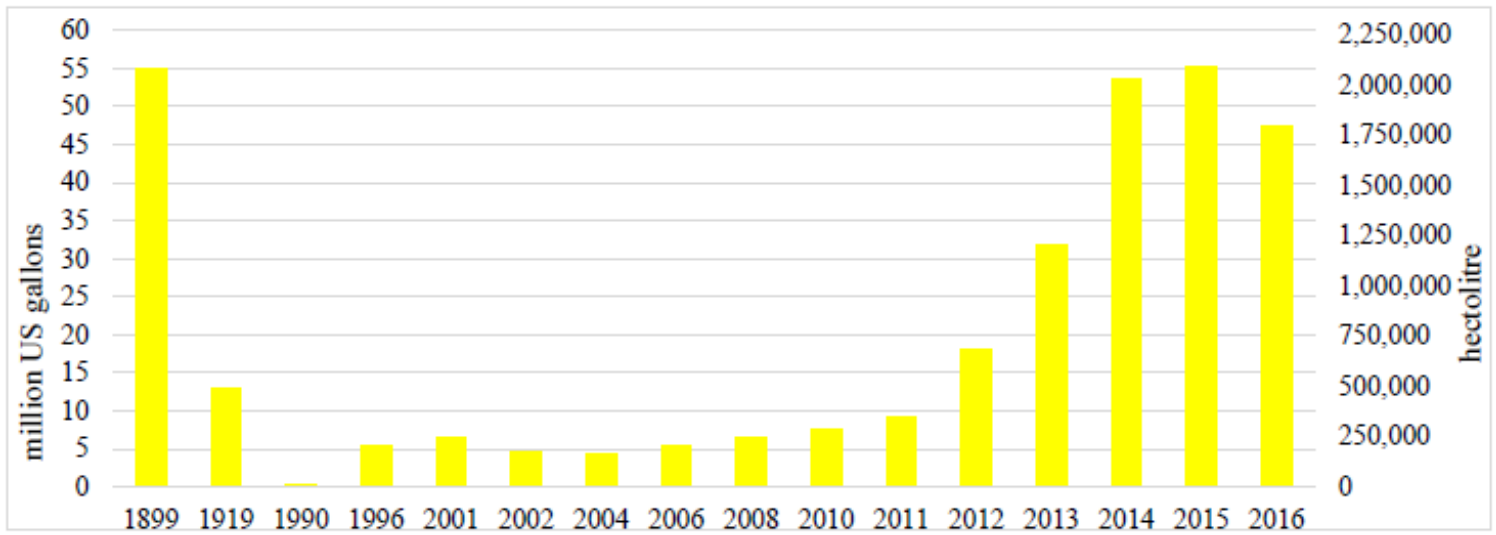

Figure 1. Hard cider production in the United States. Data prior of 2000s are from Watson (2013); data starting in the 2000s are from the TBB and account for the production of bottled hard cider for which taxes were paid

(TBB, 2017b)

The hard cider industry in the United States now confronts challenges on both the apple supply side and the hard cider demand side. With the dramatic increase in hard cider production, some U.S. cider makers have expressed concern over the limited supply of cider-specific apples in the domestic market. This gap between the supply of and the demand for cider-specific apples has been researched in several apple-producing states, including Virginia (Farris, Peck, \& Groover, 2013), Washington (Galinato, Gallardo, \& Miles, 2014), Wisconsin (Baisden, 2015), and Vermont (Becot, et al., 2016a). On the hard cider demand side, Watson (2013) notes that "[e]ven today, when interest in cider is high and sales of major commercial brands are soaring, many people don't quite know what to make of hard cider-what it should taste like, when to serve or drink it. [US-Americans], especially, are still in the process of reinventing a "cider culture." However, little research has been undertaken on the interest of cider makers in differentiating their hard cider styles, and on the demand for hard cider made with cider-specific apples (Kline \& Cole, 2017). In one of the first studies that looked at demand, Tozer et al. (2015), who studied the willingness-to-pay (WTP) of consumers for different hard cider taste profiles, noted, "Given that there are no well-defined standards to categorize [hard] cider styles, such as there are for wines, consumers are faced with a difficult task of making a [hard] cider purchase based on inconsistent information on the product label." Such confusion likely hinders the maturation of the hard cider industry.

\subsection{Vermont Hard Cider Industry}

In 2015 and 2016, the TBB ranked Vermont as the state with the highest production of bottled hard cider on which taxes were paid (with $9.8 \%$ and $8.3 \%$ of U.S. total hard cider production respectively) (TBB, 2017b). Cider makers in Vermont are diverse, ranging from independent cider makers who grow some of their apples (orchard-based cider makers), to independent cider makers who do not grow their apples (non-orchard-based cider makers), to the number two hard cider brand in the U.S. (now owned by the transnational company C\&C Group plc), which has a market share of $23.3 \%$ (Petrillo, 2016). Vermont is also the state with the most ice cider producers in the country (Vermont Ice Cider Association, 2017). As such, Vermont is a crucial player of the U.S. hard cider industry. (Note 1)

On the apple supply side, Becot et al. (2016a) demonstrated that cider makers in Vermont highly value the sourcing of apples from their state or regional (New England) markets. Due to the limited volume currently grown in these areas, Vermont cider makers who want to source more domestically grown cider-specific apples need to either enter or expand cider-specific apple production themselves, or enter strategic partnerships with apple growers that will produce the desired apples for their cidery. However, for apple growers established as dessert apples producers, the diversification of their orchards towards cider-specific production involves managerial, technical and financial challenges. Becot et al. (2016a) further suggest that orchard diversification for hard cider will bring socioeconomic gains to Vermont, including an increase in entrepreneurial activity, the creation of jobs, the enhancement of investments, and the augmentation of the Vermont brand. To concretize these gains, the authors state the need for research regarding long-term formalized contracts or other inter-organizational strategic partnerships that promote orchard diversification, while protecting both the growers' and the cideries' interests. This research project focuses on the feasibility of contracts and cooperative strategies, 
as these are the inter-organizational strategic partnerships used by world's leading industries of cider-specific apples.

On the hard cider demand side, little research has been done in Vermont or on a country-wide scale. Understanding the demand for hard cider is further complicated by the shifting identity of the beverage. For example, Citizen Cider presents their Wits Up Cider as one that, "drinks like an ale," and concurrently markets another hard cider named the bRosé as a "lovely summer rosé style cider" (Citizen Cider, 2016). Stowe Cider describes some of their hard cider as "Chardonnay [and] barrel aged cider," while Windfall Orchard declares that their Farmhouse Hard Cider is "... bottle condition for a natural bubble reminiscent of Champagne" (Stowe Cider, 2017; Windfall Orchard, 2017). Lacking a universal hard cider lexicon, cider producers use terms employed to describe other alcoholic beverages, such as beer and wine, to help guide consumers to a hard cider they will enjoy.

\subsection{Cider-Specific Apple Management by World's Leading Industries}

France, the United Kingdom, and Spain are the three principal producers of cider-specific apples in the world (FranceAgriMer, 2016a). The U.K. has the second largest area of cider-specific orchards, with 7,000 hectares that yield an average production of 200,000 tons of cider-specific apples per year (FranceAgriMer, 2016a). About $80 \%$ of cider-specific apples in the U.K. are managed under long-term contractual schemes that legally bind an apple grower and a cider maker. Such contracts can be established up to three years before the trees are planted, and they last on average 20 years (Becot et al., 2016b). These contracts frame discussions about expected yields, quality standards, delivery of fruits, rejection of fruit, pricing, price adjustment, and payment (Becot et al., 2016b). Long-term formalized contracts for cider-specific apple production is said to be a strategic partnership that is mutually beneficial for apple growers and cider makers (Macdonald, 2016).

France claims to have the largest area of cider-specific orchards with 8,700 hectares that yield an average production of 260,000 tons of cider-specific apples per year (FranceAgriMer, 2016b). The filière cidricole (French cider industry) is composed of 10,000 fruit producers, 1,500 of which grow strictly cider-specific apples. These producers are located mainly in Bretagne, Basse-Normandie and Haute-Normandie (FranceAgriMer, 2017). Two cooperatives, Agrial and Les Celliers associés, manage $85 \%$ of cidre production in France (FranceAgriMer, 2016a). Today, $80 \%$ of the cider-specific apples of the filière cidricole are produced under contracts (FranceAgriMer, 2016a). In 2004, Agrial acquired Cidreries du Calvados la Fermière (CCLF) and now owns France's largest cidre brands: Loïc Raison, Écusson and Kerisac. In 2016, Agrial acquired Seattle Cider Company. In their 2016 annual report, Agrial described this U.S. acquisition as a positioning strategy that would allow the cooperative to capitalize on the world market for the "Anglo-Saxon cider style" that is becoming increasingly popular (Agrial, 2017).

\subsection{Geographical Indication Certifications}

Fermented apple-based beverage differentiation in the global market is nothing new. It should be noted here that "cider," "cidre," "sidra," or "apfelwein" are not pure translations of terms used interchangeably to designate fermented apple beverages; they also connote different tasting experiences. For example, in the filière cidricole, cidre implies the "French-style" (a fermented beverage made exclusively from apple or pear juice, with a maximum of 50\% concentrate and no added sugar), and cider implies the "Anglo-Saxon style" (a sparkling beverage, with no limit on the use of juice concentrate and added glucose syrup) and is described as a "beer alternative" (FranceAgriMer, 2016a).

A popular differentiation mechanism used by fermented apple-based beverage industries is geographical indication certifications (GIs) (see Table 2). GIs can protect both consumers and producers against fraud: because registered labels are regulated by a code of practices that has been verified by authority figures, GI products indicate authenticity to consumers and guarantee that the product is genuine. At the same time, GIs insure producers against free-riding "imitators" (Hopper, Costley, \& Friend, 2015; Teuber, 2009). As such, GIs provide a competitive advantage to producers as they, "create[s] an image of 'exoticness,' or scarcity that enables them to obtain premium prices for products that would otherwise be ascribed commodity status. The main source of this exoticness comes from unique quality differences that may be attributed to production in a particular geographical area based on quality characteristics associated with that location" (Agarwal \& Barone, 2005).

In their review of the pros and cons of GIs, Giovannucci, Josling, Kerr, O'Connor, \& Yeung (2009) offer the following conclusion: "[GIs can] be a unique and powerful tool when adequately managed. GIs can offer a comprehensive framework for rural development since they can positively encompass issues of economic competitiveness, stakeholder equity, environmental stewardship, and socio-cultural value." Among the rural development potentials listed are: "better quality rural employment," "foster business clustering and rural 
integration," and increased tourism (Giovannucci et al., 2009). The authors further indicate that the downsides of GIs are largely attributed to bad management: "badly managed GIs can be dominated by limited political interests or just a few enterprises. In some cases, GIs can exclude the poorest producers or even stimulate inappropriate outcomes such as the dissolution of traditional practices or the destruction of biodiversity" (Giovannucci et al., 2009). Giovannucci and his colleagues identify four essential components to the success of GIs: (1) strong organizational and institutional structures to maintain, market, and monitor the GI; (2) equitable participation among the producers and enterprises in a GI region; (3) strong market partners committed to promoting and commercializing over the long term; and (4) effective legal protection, including a strong domestic GI system.

Registered GIs are instruments to facilitate free trade, and as such are regulated by international organizations like the Court of Justice of the European Communities and the World Trade Organization (Broude, 2004). However, Giovannucci et al. (2009) indicate that in the United States, "even unregistered GIs may be recognized as common law marks and thus be enforceable if they rise to the level of a 'source identifier'," which they define as a "trademark term meaning the capacity of a sign to clearly distinguish the goods or services of one enterprise (including a collective group of producers) from those of another enterprise." Florida Oranges, Idaho Potatoes, Maine Lobster, Napa Valley Wine, and Washington State Apples are all examples of preeminent GI brands active in the United States (Agarwal \& Barone, 2005). There are no GIs for hard cider.

Although GIs are largely based on places of production, they also regularly contain process-based regulations. For example, two categories of sidra are marketed under the Sidra de Asturias GI: sidra and sidra natural. Their differences are largely based on process. Official documentation indicates that "traditional" techniques must be used to market under the sidra natural GI. Traditional techniques include wild yeast fermenting, no-filtration bottling, no added $\mathrm{CO}_{2}$, and no added sugar (Ministerio de Agricultura y Pesca, 2017). Overall, 93\% of the Sidra de Asturias production is sidra natural, $90 \%$ of which is made by independent orchard-based cider makers (Muñoz de Escalona, 2011).

As shown on Table 1, GIs are largely used in Europe. In the United States, as already detailed above, hard cider is regulated as a wine by the TBB. The TBB regulation does contain some GI guidelines in its "Wine Appellations of Origin" section (TBB, 2017c), but the regulations would not be adapted to the hard cider context according to several cider makers that participated in this research project. States and counties are authorized to label under the wine appellation of origin regulations. Several counties in the same wine producing area can collectively register as an American Viticultural Area (AVA). As of November, 20 ${ }^{\text {th }}$ 2016, there were 239 established AVAs in the United States, 17 of which are multi-state AVAs (TBB, 2016).

Table 1. GI certifications for fermented apple-based beverages

\begin{tabular}{lll}
\hline Country & Protected Product & Registered Date \\
\hline United Kingdom & Gloucestershire cider & 1996 \\
United Kingdom & Herefordshire cider & 1996 \\
United Kingdom & Worcestershire cider & 1996 \\
France & Cidre de Bretagne & 2000 \\
France & Cidre Cornouaille & 2000 \\
France & Cidre de Normandie & 2000 \\
France & Pays d'Auge ; Pays d'Auge-Cambreme & 2000 \\
Spain & Sidra de Asturias & 2005 \\
France & Calvados & 2008 \\
Germany & Hessischer Apfelwein & 2010 \\
Canada & Cidre de Glace du Québec & 2014 \\
United Kingdom & Traditional Welsh Cider & 2017 \\
Finland & Verlados & In review \\
Spain & Euskal Sagardoa / Sidra Natural del País Vasco & In review \\
France & Cidre Cotentin & In review \\
\hline
\end{tabular}

Note. Data from the European Commision database and the Conseil des appellations réservées et des termes valorisants.

In addition to highlighting the place of production or the process, there are other means of differentiating hard ciders. Since 2014, cider makers in Bretagne have held an annual blind tasting contest. In this year's competition, 130 samples spread across 15 different categories were assessed by 88 judges (La maison cidricole de Bretagne, 
2017a). A point system based on pre-defined criteria determines which cidre will be honored a medal each year. La maison cidricole de Bretagne, an organization of cider makers from Bretagne, indicates that these distinctions act as true reference points for consumers (La maison cidricole de Bretagne, 2017b). In the United States, the Great Lakes International Cider and Perry Competition (GLINTCAP) organizes an annual competition that is not regional like the one in Bretagne, nor exclusive to U.S. hard ciders; it is an international competition. Such a competition is thus not designed to distinguish between hard styles in the United States per se. Finally, it is important to mention that some differentiation mechanisms, like the Sidra de Manzana Seleccionada certification (a certification that is supplemental to the Sidra de Asturias GI), incorporates place, process and taste regulations (Sidra de Manzana Seleccionada, 2017).

This paper addresses a gap in the literature regarding the coordination of the hard cider supply chain, through two research questions: (1) are long-term contracts and cooperative strategic partnerships suitable to the Vermont hard cider industry to stimulate cider-specific apple production, and (2) are cider makers in Vermont interested in working under a geographical indication certification (GI) to differentiate their hard cider styles and increase demand for hard ciders made with cider-specific apples.

\section{Methods}

This study was conducted using a mixed methods approach. Using fourteen semi-structured and open-ended interviews, the first part of the project explores the perspectives of apple growers, cider makers, and other key industry stakeholders on stimulating cider-specific apple production in Vermont. The second part of the project summarizes the results from an online survey that measured the interest of cider makers in Vermont in working under several types of GIs. Table 2 provides a summary of the methods used, associated research questions, and participants.

Table 2. Method used, the associated research question, and participants

\begin{tabular}{lll}
\hline Mixed Methods & Research Questions & Participants \\
\hline \multirow{2}{*}{$\begin{array}{l}\text { Semi-structured } \\
\text { interviews }\end{array}$} & $\begin{array}{l}\text { Are long-term contracts and cooperative strategic } \\
\text { partnerships suitable to the Vermont hard cider } \\
\text { industry to stimulate cider-specific apple production? }\end{array}$ & $\begin{array}{l}5 \text { apple growers } \\
6 \text { cider makers } \\
\text { 3 other industry stakeholders }\end{array}$ \\
\hline \multirow{2}{*}{ Online survey } & $\begin{array}{l}\text { Are cider makers in Vermont interested in working } \\
\text { under a geographical indication certification (GI) to } \\
\text { differentiate their hard cider styles? }\end{array}$ & $\begin{array}{l}9 \text { out the 14 Vermont cider makers } \\
\text { listed by the Vermont Tree Fruit } \\
\text { Growers Association }\end{array}$ \\
\hline
\end{tabular}

\subsection{Interviews}

For the first part of the project, data were collected through fourteen semi-structured interviews conducted with Vermont hard cider industry stakeholders. The director of the UVM Horticulture and Research and Education Center acted as a key informant and provided the research team with contacts. Maximum variation sampling (Patton, 2015) was used to ensure a wide representation of stakeholders and to minimize biases that could arise by only interviewing one particular group of stakeholders. For apple growers, the variation criteria was based on orchard acreage to ensure that all types of apple production operations were represented in the study. Participants ranged from growers who manage fewer than 15 acres and focus mainly on the "pick-your-own" market, to growers that have 200 acres or more in production and focus primarily on the wholesale market, to growers who sell to both markets. For cider makers, the variation criteria were based on the type of operation (orchard-based cideries, and non-orchard-based cideries) to capture the perspectives of all types of operations and hard cider styles. In total, the project included five apple growers, six cider makers, and three other stakeholders (the former president of the Vermont Tree Fruit Growers Association, one of the owners of an apple storage facility, and the executive director of the Vermont Fresh Network). To ensure anonymity of participants evolving in this small and tightly-knit industry, further particularities or potential biases cannot be provided here. As such, the variation criteria listed above will serve to provide generic categorization profiles for participants.

Participants were interviewed between February and September 2016. One cider maker and one apple grower selected were located just outside Vermont borders, but were included in the project as they were identified by many stakeholders as highly connected to and influential in the Vermont hard cider industry. Long-term formalized contracts and cooperative models were the two main strategic partnership mechanisms presented, although the semi-structured interview format allowed for other strategies to be discussed. The interview guides were inspired by the strategic partnerships that are in place in the well-established cider-specific apple industries of the United Kingdom (long-term formalized contracts), and France (cooperative). The interview protocols were 
approved by the University of Vermont Committees on Human Subjects (IRB\#16-358) and were classified as "exempt."

Eleven interviews were conducted in person, two were conducted over the phone, and one over email. Interview recordings were 52 minutes on average; the shortest one is 20 minutes and the longest one is 90 minutes. Interviews were transcribed verbatim for open-coding analysis of emerging themes in HyperResearch 3.7.3. The codes created for the analysis were generated to link the data to the specific research objectives, namely to measure interest in establishing strategic partnerships within the Vermont hard cider industry to stimulate cider-specific apple production in the state. In addition, sub-codes related to diversification barriers and infrastructure needs were used to identify motives for interest in strategic partnerships.

\subsection{Survey}

In November 2016, an online survey was sent to all fourteen Vermont cider makers listed by the Vermont Tree Fruit Growers Association to measure interest in the introduction of a label that would differentiate and define hard cider styles. The survey was open from November 2016 to February 2017. Out of the fourteen cider makers contacted, nine participated. The survey was designed using elements of GI certification of the world's leading cider industries. Three types of labels were proposed: a place-based label, a process-based label, and a taste-based label. An open-ended question allowed participants to elaborate on their answers. The survey did not specify the process for establishing or managing the proposed labels. The intent of this research project is not to establish a specific labeling regime, but rather to foster further discussion and research regarding the demand in Vermont and the U.S for hard cider made with cider-specific apples.

The place-based label proposed by the survey identified the Lake Champlain watershed area as a hard cider AVA (see figure 3), and the Vermont State borders were suggested to serve as an appellation of origin. The Champlain Valley and the state of Vermont were referred to by several cider makers as their perceived apple growing regions during the interview process. Testing a label that specified the Lake Champlain watershed area-which encompasses the Champlain Valley - was decided upon by the research team as a way to make the largest number of cider makers in Vermont feel included in GI conversations, while staying within a single growing region. In addition, some of the place-based labels tested also included process-based standards, which served to differentiate hard cider styles within a defined place. The survey also tested a label that indicated only process-based standards that could be applied regardless of production area. Finally, the survey asked Vermont cider makers to indicate their interest in working under a taste-based label that would be built around blind tasting procedures designed to differentiate between hard cider styles.



Figure 2. One of the hard cider AVA proposed: The Lake Champlain watershed area. Map from Google Earth4. Results 


\subsection{Interviews' Results}

\subsubsection{Cooperative}

For the most part, interviewees were wary of the idea of using a cooperative model for coordinating cider-specific apple production. About a decade ago, an apple growers cooperative was shut down. The Shoreham Coop (1946-2002) was a storing, packaging and marketing hub that handled at its peak (in 1986) about half of Vermont apple production. Interviewees listed mismanagement and the apple industry crash of the 1990s as the primary factors that forced the coop to shut down. As a result of the relatively recent Shoreham Coop collapse, interviewees were not enthusiastic about the strategy of forming a new cooperative, even though it might facilitate cider-specific apple production by allowing growers to share infrastructure. Here is how an apple grower verbalized the matter: "Short term I think a lot of growers would be pretty apprehensive about entering in any kind of coop (...) there is still some bad feelings about the coop in Shoreham that felt apart, and guys might not be willing to... for some guys it is still very fresh to their memories so they are maybe feeling bitter about what happened there" (Apple Grower 1). Discussions regarding the cooperative model felt short with both apple growers and cider makers, and expressed interest was low.

\subsubsection{Contracts}

In the present-day Vermont cider industry, most of the apple sales between apple growers and cider makers are made through what interviewees referred to as "handshake agreements." Handshake contracts are embedded in the current apple agricultural practices of Vermont; they are very appealing to growers who have a desire for independence and flexibility. Although several interviewees indicated that discussions have taken place regarding making handshake agreements more formal by making them written, the strong cultural ties of current apple growers to handshake agreements is a key factor preventing contract formalization in Vermont. An orchard-based cider maker reported: "[apple growers] prefer to remain independent ... so our partnerships are built the good old fashion way, on relationship and a handshake, and on honoring of these commitments year over year" (Cider Maker 6). As detailed hereafter, orchard scale and cider-specific apple prices are, with the handshake culture, the other two main elements preventing the formalization of contracts.

\subsubsection{Contract Scale}

Regarding scale, an orchard-based cider maker asserted: "Every time we sit down and try and think about structuring an agreement, the issues are: the scale is too small, what happens if there's a hailstorm? A big contract makes sense when you have like a Bulmers in Ireland that can guarantee a market for 2 million bushels of fruit" (Cider Maker 3). The way orchards operate in Vermont is vastly different as compared to the orchards from whom Bulmers sources their cider-specific apples. Apple growers expressed that growing cider-specific apples is an endeavor that requires means of production that are very different from how their orchards are currently organized for the production of dessert apples: "I think that is the problem, right, it is a different culture for growing cider apples than the culture of growing conventional apples... an orchard with hard cider in mind, it has to be separate, it has to be its own entity. Either the cider block is like a detriment to your conventional orchard, or you are putting the same amount of money and you are cutting your margins down" (Apple Grower 5). Some growers expressed fear of contamination of dessert blocks from cider blocks: "Replanting just cider-specific is not going to happen. Because I do not know any varieties that would not be obliterated by fire-blight" (Apple Grower 4). This is because cider blocks (which aim at producing juice) require less pesticide applications and overall maintenance than dessert apple blocks (which aim at producing apples with high cosmetic standards).

\subsubsection{Contract Pricing}

Regarding price within long-term formalized contracts, a non-orchard-based cider maker indicated that the same issue preventing cull (a word that refers to low-grade dessert apples) contracting would likely arise with contracts for cider-specific apples: "It's something to look towards in the future, but right now there is really no value for a grower to be in a contract for cull pricing, nor is there for cider makers to agree to a price for culls, because they may swing widely" (Cider Maker 4). Apple growers stated that prices for cider-specific apples are uncertain over the long-term, especially compared to the prices for dessert apples, on which they have relied for years. Many growers were skeptical that the current high value for cider-specific apples will persist as more and more growers start producing them. Cider makers are also reluctant to engage in long-term formalized contracts for cider-specific apples because of the low perceived demand for hard cider made with cider-specific apples: "The problem is...this would all be easy if we could sell cider for $\$ 25$ a bottle. This would go away. There is only $1 \%$ of cider makers who are selling hard cider for a price that can justify the contract, so this is completely theoretical in the U.S. market" (Cider Maker 4). To balance financial risk and encourage orchard diversification, several apple growers and cider makers expressed the need for financial and technical support from university 
extension to create a cider-specific growing program.

Table 3. Summary of the interest of interviewees regarding the use of long-term formalized contracts in stimulating cider-specific apple production

\begin{tabular}{ll}
\hline Participant & Long-term formalized contract interest \\
\hline Apple Grower 1 & for dual-purpose \\
Apple Grower 2 & none \\
Apple Grower 3 & none \\
Apple Grower 4 & none \\
Apple Grower 5 & for dual-purpose \\
\hline Cider Maker 1 (orchard-based) & none \\
Cider Maker 2 (orchard-based) & none \\
Cider Maker 3 (orchard-based) & none \\
Cider Maker 4 (not orchard-based) & eventually \\
Cider Maker 5 (not orchard-based) & interested \\
Cider Maker 6 (not orchard-based) & none \\
\hline Stakeholder 1 & eventually \\
Stakeholder 2 & eventually \\
Stakeholder 3 & no opinion \\
\hline
\end{tabular}

\subsubsection{Demand for Hard Cider Made with Cider-Specific Fruits}

The emerging theme from these interviews regarding long-term formalized contracts is that the core issue preventing cider-specific apple production in Vermont is on the hard cider demand side, rather than on the apple supply side. One non-orchard-based cider maker indicated: "Currently fruit-flavored ciders made from dessert apples are the dominant growth area for cider, along with the addition of hops and ginger" (Cider Maker 4). An orchard-based cider maker expressed how, "there's nothing special about the apples in relationship to that cider and where the growth right now is in these ciders that are made from leftover dessert fruits, and boy those are apples that people know how to grow, they are already doing it (...) Where is the demand for super unique expensive fruit?" (Cider Maker 3).

\subsubsection{Establishing Completely New Cider-specific Orchards}

The semi-structured interview format allowed for another strategy (other than long-term formalized contracts and cooperatives) to be discussed: the establishment of completely new orchards, operated strictly for hard cider production. This solution generated positive feedback across all interviewee profiles, from orchard-based cider maker: "That would be a totally new orchard, and I think there is a lot to be said for that" (Cider Maker 1), to apple grower "To me that seems like the most clear-cut way to do it" (Apple Grower 5). In regards to establishing new orchards, a non-orchard-based cider maker said, "We would have to partner or hire whole bunch of expertise that we don't currently have to do that, but you know, things change" (Cider Maker 4). One apple grower indicated that some newcomers have been testing the idea of partnerships for establishing cider-specific orchards: "there were some people that wanted to be partners and plant 100 acres of that hard cider apples (...) all mechanically harvested, so that they have virtually no labor. They would have a big press running 24 hours a day and machines picking the apples (...) they had 2 million dollars to start with" (Apple Grower 2).

\subsubsection{Differentiating Hard Cider}

Many cider makers were adopting a differentiation rationale. This differentiation narrative is essential to the development of convincing GI labeling. The affirmation of their distinctiveness (from European ciders) is clearly articulated in the following quote taken from an interview conducted with a pioneer of the hard cider revival in the American Northeast:

"But there was a time in the late 90s or about 2000 when people were tasting and we were just beginning to learn how to actually do sensory analysis, we have not got really far down that road, but we started to say to each other: we are encountering aromas and flavors and feels in this cider that we are making from this fruit grown here that we never encountered in England, France, or anywhere else. And then it was really just why the fuck are we trying to do something imitative. Why don't we just say: right, we are apple growers, we found some really good stuff that grows that we think make really good cider, and now we are going to make something that is delicious by our likes, and that we think that is reflective of our fruits, and the land on which is grown and what we do there" (Cider Maker 2). 
In other words, there are cider makers in the American Northeast who have developed hard cider with unique characteristics, and which differ from European ones. Such unique characteristics may provide a competitive advantage as consumers become aware of them.

\subsubsection{Apple Supply Summary}

In short, the interviews established that the current culture of handshake agreements, the relatively low volume of apples produced by apple growers, the price point for cider-specific apples, and the lack of cider-specific growing experience in the state make the notion of long-term formalized contracts ill-adapted to today's Vermont hard cider industry. The interviews also indicated that the recent collapse of the Shoreham Coop makes current hard cider actors distrustful of using this strategy to stimulate cider-specific apple production. A potential solution that has emerged from the interviews is the establishment of completely new orchard enterprises dedicated only to cider-specific apple production.

\subsection{Survey's Results}

Participating cider makers unanimously agreed that helping consumers differentiate between hard cider styles would benefit the Vermont hard cider industry. When asked which of the three proposed labels they would prefer to work under, five cider makers indicated place-based label, two indicated the taste-based label, and one indicated the process-based label. One cider maker did not specify any preference, and in fact rejected any place-based label. However, by analyzing the rest of the survey's data-which measures interest in each label instead of preference between the labels - a taste-based label generated more consensus, followed by a place-based label and a process-based label. Below is the breakdown of the expressed interest for each proposed label.

Table 4. GIs interests and preferred based

\begin{tabular}{|c|c|c|c|c|}
\hline Cider Makers & Place-Based & Process-Based & Taste-Based & Preferred Based \\
\hline A & $\begin{array}{l}\text { Interested } \\
\text { (Champlain Watershed) }\end{array}$ & Interested & Very interested & Place-Based \\
\hline B & Not interested & Somewhat interested & Interested & Process-Based \\
\hline $\mathrm{C}$ & $\begin{array}{l}\text { Interested } \\
\text { (Other Disjointed Areas) }\end{array}$ & Very interested & Very interested & (no answer) \\
\hline $\mathrm{D}$ & $\begin{array}{l}\text { Interested } \\
\text { (Other Disjointed Areas) }\end{array}$ & Interested & Interested & Place-Based \\
\hline $\mathrm{E}$ & $\begin{array}{l}\text { Very interested } \\
\text { (Vermont state border) }\end{array}$ & Interested & Very interested & Place-Based \\
\hline $\mathrm{F}$ & $\begin{array}{l}\text { Somewhat interested } \\
\text { (Vermont state border) }\end{array}$ & Somewhat in Interested & Interested & Taste-Based \\
\hline G & $\begin{array}{l}\text { Very interested } \\
\text { (Vermont state border) }\end{array}$ & Very interested & Very interested & Place-Based \\
\hline $\mathrm{H}$ & $\begin{array}{l}\text { Interested } \\
\text { (Vermont state border) }\end{array}$ & Not at all interested & Not at all interested & Place-Based \\
\hline I & Not interested & Somewhat in interested & Very interested & Taste-Based \\
\hline
\end{tabular}

\subsubsection{Taste-Based}

In the survey, a taste-based label was described as one that focuses exclusively on the final taste of a hard cider. Defined taste standards for different hard cider styles were not detailed, as these would have to be defined and certified by a panel of elected judges. All participating cider makers but one were either interested or very interested in submitting some of their hard ciders to an annual tasting evaluation with a panel of judges that would assess if their hard ciders qualified to be sold under a taste-based label. In the open-ended section of the survey, one of the cider makers interested in a taste-place label submitted an alternative labeling mechanism to an annual judging competition: "[a label that would have for visual] a multi-dimensional scale that would define standard levels represented by a label with a circle with four quadrants, where the quadrants have [a standard] indicator for sweetness, tartness, tannin, and fizz levels...such taste-based label is easiest to implement because it doesn't 'judge' quality of cider, and it does the most to help consumers identify a cider they will enjoy drinking...If we can all agree on a taste indicator, then it will have the full weight of all our cideries behind it" (Cider Maker I). 


\subsubsection{Place-based}

A place-based label was described in the survey as one that differentiates a cider by putting forward a story of the unique characteristics of a place - or terroir. Within the place-based label, two process-based subcategories were proposed to further differentiate between the hard cider styles produced within a single area. Four cider makers expressed interest in working under a label based on the Vermont state borders, one under a label based on the Lake Champlain watershed area, two under a label based on more disjointed areas delineated by growing conditions, and two cider makers rejected the idea of working under a place-based label. In terms of process regulations contained within a place-based label, all participating cider makers (but one) agreed that under a place-based label, certified hard ciders should be made $100 \%$ from apples grown within the chosen area; the participant who did not agree suggested a threshold of $75 \%$. In addition, all participating cider makers (but one) indicated that under a place-based label, certified hard cider would have to be made from $100 \%$ fresh-pressed apples. Six cider makers also indicated that to be certified, a ciderie would have to be located within the chosen area; two were unsure regarding this parameter, and one was opposed. Furthermore, five cider makers were in favor of having two subcategories in a place-based label that would categorize hard cider by style by imposing additional processing standards.

\subsubsection{Process-based}

A process-based label was described in the survey as one that does not focus on a particular area of production, but rather exclusively on the types of fruit and processes used, in a way that such a label could be used by any cider maker in the United States. The different sets of standards that would serve to differentiate between hard cider styles were not fully developed in the survey. Five cider makers indicated being either in favor or strongly in favor of working under a process-based label, three indicated being somewhat in favor, and one was not at all in favor.

\section{Discussion}

The goal of this research project was to gauge the interest of hard cider industry stakeholders in various strategies to stimulate the production of cider-specific apples domestically, as well as to explore stakeholder interest in GI labeling to differentiate between hard cider styles. Overall, the findings of this study indicate that before investing in planting cider-specific apple trees, there must be a plan in place to increase demand for hard ciders made with cider-specific apples. The recent decline of hard cider production in the U.S. reinforces the need for marketing strategies that aim at retaining and growing consumer demand.

Semi-structured interviews focused on the interest in and feasibility of strategic partnerships, specifically long-term formalized contracts and cooperatives, and established that both mechanisms are ill-adapted to the current Vermont hard cider industry context. In contrast to the cider industry in the U.K. and France, the current scale of the industry in Vermont is not conductive to using formalized long-term contracts. The Vermont hard cider industry is still emerging, and the value of cider-specific apples remains uncertain in the long-term, undermining the utility of long-term formalized contracts. Regarding cooperatives, the recent shutdown of the Shoreham Coop makes most stakeholders distrustful of a cooperative strategy. As such, the use of cooperative models involving experienced stakeholders is improbable in the short term-although follow-up research might prove otherwise as the Vermont hard cider industry reach maturity, or as new stakeholders establish themselves. Establishing completely new orchards dedicated to cider-specific apple production, which would increase the production of cider-specific apples domestically, was further identified as an alternative to long-term formalized contracts and cooperatives.

The surveys established that cider makers are ready to develop and introduce GI labels to differentiate between their hard cider styles, and increase consumer demand and literacy for hard cider made with cider-specific fruits. The cider makers surveyed were unanimously in favor of establishing some kind of differentiation mechanism, and both place-based and taste-based labels were identified as being of high interest. Process-based labels were also of interest, but more as a complement to a taste-based or place-based label rather than as a label that stands on its own. Although participants did not agree on a particular area for a place-based label, this research project provides useful data to inform and foster further discussions surrounding hard cider GI label development. Researching and interviewing cider makers for the present project, it became evident that the hard cider culture in Vermont does not stand as its own, but actually considers itself part of a broader hard cider culture that transcends Vermont state political borders.

As detailed in the literature review, GIs can serve as more than a differentiation tool; when properly managed, they can be a powerful economic development tool generating jobs and tourism, and can promote rural business clustering. The hard cider industry possesses all of the assets required by Giovannucci et al. to initiate the 
development of successful hard cider GIs in the U.S. The first component, having "strong organizational and institutional structures to maintain, market, and monitor the GI," could be fulfilled by the United States Association of Cider Makers, or by a regional branch created specifically for regulating hard cider GIs in a particular region. In regards to the second and third assets listed by Giovannucci et al. ("equitable participation among the producers and enterprises in a GI region" and "strong market partners committed to promote and commercialize over the long term"), this research project indicates that cider makers from all types of profiles are willing to work under a GI in the area of study. This strong interest is a promising first step towards the inclusion of all actors in the development and management of a hard cider GI. In terms of the last component (effective legal protection including a strong domestic GI system), there are already other GI examples in place the U.S.

A GI for hard cider has the potential to succeed where long-term formalized contracts and cooperatives appear to be ill-adapted to the Vermont context. Agarwal \& Barone (2005) indicate that when GIs are introduced, "new entrants will enter the geographical area to take advantage of the brand equity residing in the GI." The stimulation of cider-specific apple production could come with the introduction of a hard cider GI, which may attract new cider makers and related businesses to the area. This could lead to the development of a cluster of orchard-based cideries eager to capitalize on the competitive advantage provide by the GI, and may also bring enterprises with the capital to build completely new cider-specific orchards in the region specified by the GI.

In all cases, a marketing campaign is likely necessary if the hard cider industry goes forward with the introduction of GIs. Confronted with a decrease in demand for cidre, FranceAgriMer (2016a) prepared a report for the filière cidricole in France in which it suggested increasing the demand for cidre through a marketing campaign based on cidre distinguishing "authenticity," that would differentiate cidre from the increasingly popular "Anglo-Saxon cider style." A similar differentiating campaign would likely be necessary in the U.S. The socio-historical elements surrounding the revival of a beverage that was once labeled the "national drink" provide a compelling narrative for such a marketing campaign.

\section{Conclusion}

This research project has identified the establishment of a hard cider GI as the most promising strategy-compared to long-term formalized contracts and cooperatives - to tackle both cider-specific apple supply issues and hard cider demand challenges. The focus of the GI label introduced in this study was the American Northeast, more precisely Vermont and its surroundings, but the findings have implications for the whole U.S. industry. It should be noted here that although the research team made sure to study a wide variety of stakeholder profiles to limit biases, the content of the results section only reflects the views of those who participated - whom are likely stakeholders who had stronger opinions to voice and who enjoy taking surveys.

Although not all Vermont cideries answered the survey, the high response rate and the shared interest expressed by participants for the introduction of a GI indicate that the hard cider industry in the area of study is mature enough to initiate the development of a GI certification. The discussion section of this research paper has further established that the U.S. hard cider industry possesses all the assets required for the successful implementation and management of one - and potentially several — hard cider GI(s). This research project has also detailed how a GI can act as a powerful economic development tool. Measuring the interest of the rest of the U.S. hard cider industry would thus be valuable to locate other areas and additional cideries interested in hard cider GI discussions.

In addition to providing evidence that the right conditions exist for the establishment of a hard cider GI in the U.S., this research project has laid the groundwork for the development of a GI in the Northeast region. The discussions between the research team and the participants have jump-started the conversation regarding the appropriate basis for a Vermont GI (place-based, taste-based, or process-based). This study has detailed how such a GI could include more than one parameter; for example, a hard cider GI that is taste-based, with each taste further associated with a particular area and the result of a certain process. Ultimately, it is up to cider makers and their associations to further develop a hard cider GI regime and to delimit appropriate tastes, areas or processes.

\section{Acknowledgements}

We would like to thank all participating apple growers and cider makers for taking the time to participate in this research project. Thanks to Amy Trubek, Shoshanah Inwood and Florence Becot for the feedback provided and to Emily Irwin for the editing help. Nicolas would also like to acknowledge the financial support received from the Fonds de recherche du Québec - Société et culture (FRQSC). 


\section{References}

Agarwal, S., \& Barone, M. J. (2005). Emerging Issues for Geographical Indication Branding Strategies. MATRIC Research Papers, (paper 5).

Agrial. (2017). Rapport annuel 2016. Caen. Retrieved from http://www.agrial.com/publications/

Baisden, H. (2015). Growing Cider in Wisconsin. Should Wisconsin Apple Growers Grow Cider Apples? Chicago, Illinois.

Becot, F., Bradshaw, T., \& Conner, D. (2016a). Apple Market Expansion through Value-added Hard Cider Production: Current Production and Prospects in Vermont. HortTechnology. Retrieved from http://horttech.ashspublications.org/content/26/2/220.short

Becot, F., Bradshaw, T., \& Conner, D. (2016b). Fact Sheet: Long-Term Contracts in the UK Cider Industry. Retrieved from http://www.uvm.edu/ fruit/treefruit/tf_cider/UVM_UK_ciderapplecontracts.pdf

Broude, T. (2004). Taking "trade and culture" seriously: Geographical indications and cultural protection in WTO law. Journal of International Law, 26(4), 623-692. https://doi.org/10.2139/ssrn.714981

Citizen Cider. (2016). The AmeriCran's Cranberry Bob Bog Blog. Retrieved from http://www.citizencider.com/2016/10/the-americrans-cranberry-bob-bog-blog/

Farris, J., Peck, G., \& Groover, G. (2013). Assessing the Economic Feasibility of Growing Specialized Apple Cultivars for Sale to Commercial Hard Cider Producers. Charlottesville, Virginia. Retrieved from http://extension.psu.edu/plants/tree-fruit/presentations/hard-cider-production-workshop/economic-feasibilit y-for-hard-cider

FranceAgriMer. (2016a). Prospective filière française $d u$ cidre. Montreuil, France. Retrieved from http://www.franceagrimer.fr/content/download/45570/434561/file/Etude_Prospective filière française du cidreDEF.pdf

FranceAgriMer. (2016b). Rapport d'activité 2016. Montreuil. Retrieved from www.franceagrimer.fr

FranceAgriMer. (2017). Production. Retrieved from http://www.franceagrimer.fr/index.php/filiere-vin-et-cidriculture/Cidriculture/La-filiere-en-bref/Production

Galinato, S., Gallardo, K., \& Miles, C. (2014). 2013 Cost Estimation of Establishing a Cider Apple Orchard in Western Washington (Vol. FS141E). Washington, Oregon. Retrieved from https://pubs.wsu.edu/ItemDetail.aspx?ProductID=15707

Giovannucci, D., Josling, T., Kerr, W., O’Connor, B., \& Yeung, M. T. (2009). Guide to geographical indications: linking products and their origins. Geneva, Switzerland: International Trade Centre. https://doi.org/10.2139/ssrn.1736713

Hopper, D., Costley, C. L., \& Friend, L. A. (2015). Embodied self-authentication. Australasian Marketing Journal (AMJ), 23(4), 319-324. https://doi.org/10.1016/j.ausmj.2015.10.007

Kline, C., \& Cole, Z. D. (2017). Craft Cider Tourism: Getting to the Core of the Matter. In C. Kline, S. L. Slocum, \& C. T. Cavaliere (Eds.), Craft Beverages and Tourism, Volume 1 (pp. 41-55). Cham: Springer International Publishing. https://doi.org/10.1007/978-3-319-49852-2_4

La maison cidricole de Bretagne. (2017a). La maison cidricole de Bretagne. Retrieved from http://www.lescidresbretons.com/

La maison cidricole de Bretagne. (2017b). Palmarès 2017 du concours régional des produits cidricoles de Bretagne. Retrieved from http://www.datapressepremium.com/rmdiff/2009001/MCB_CP_Palmares.pdf

Lyson, Thomas, A., George, W. Stevenson, \& Rick Welsh. (2008). Food and the Mid-Level Farm. Cambridge, Mass and London, England: The MIT Press. https://doi.org/10.7551/mitpress/9780262122993.001.0001

Macdonald, N. (2016). Cider Orchards : the Great British Success Story. Retrieved from http://nuffieldinternational.org/live/

McGee, H. (2004). On food and cooking: the science and lore of the kitchen. New York, NY: Simon and Schuster.

Ministerio de Agricultura y Pesca, A. y M. A. (2017). D.O.P. Sidra de Asturias/Sidra d'Asturies. Retrieved January 1, 2017, from 
http://www.mapama.gob.es/es/alimentacion/temas/calidad-agroalimentaria/calidad-diferenciada/dop/varios/ DOP_sidra.aspx

Mitchell, P. (2012). The Cider Market \& Industry - 2012 Northwest Cider \& Perry Seminar. Retrieved from http://www.agbizcenter.org/FilesUploaded/file/nabc-seminar-dec2012v2 Mitchell's presentation.pdf

Muñoz de Escalona, F. (2011). La sidricultura asturiana como incentivacion turistica (Vol. 4).

Patton, M. Q. (2015). Qualitative Research \& Evaluation Methods: Integrating Theory and Practice (4th ed.). SAGE Publications, Inc. Retrieved from https://us.sagepub.com/en-us/nam/qualitative-research-evaluation-methods/book232962

Petrillo, N. (2016). Bitter but sweet: Sales of hard cider have plateaued following years of unprecedented growth. IBISWorld Industry Report OD5335, (March).

Sidra Manzana Seleccionada. (2017). Sidra Manzana Seleccionada - Hacemos. Retrieved from http://www.sidramanzanaseleccionada.com/somos/hacemos-3/?lang=en

Stowe Cider. (2017). Our Ciders. Retrieved from https://www.stowecider.com/ciders

TBB (Alcohol and Tobacco Tax and Trade Bureau). (2016). Established American Viticultural Areas. Retrieved from https://www.ttb.gov/wine/us_by_ava.shtml\#Table-2

TBB (Alcohol and Tobacco Tax and Trade Bureau). (2017a). Electronic Code of Federal Regulations - Title 27: Alcohol, Tobacco Products and Firearms. Retrieved from https://www.ecfr.gov/cgi-bin/text-idx?c=ecfr\&sid=506cf0c03546efff958847134c5527d3\&rgn=div5\&view= text\&node=27:1.0.1.1.19\&idno=27\#se27.1.24_110

TBB (Alcohol and Tobacco Tax and Trade Bureau). (2017b). Wine Statistics. Retrieved from https://www.ttb.gov/wine/wine-stats.shtml

TBB (Alcohol and Tobacco Tax and Trade Bureau). (2017c). Wine Appellations of Origin. Retrieved January 1, 2017, from https://www.ttb.gov/appellation/

Teuber, R. (2009). Producers' and Consumers' Expectations towards Geographical Indications - Empirical Evidence for Hessian Apple Wine. Justus- Liebig University Giessen, Germany, 1-18.

Tozer, P. R., Galinato, S. P., Ross, C. F., Miles, C. A., \& McCluskey, J. J. (2015). Sensory Analysis and Willingness to Pay for Craft Cider. Journal of Wine Economics, 10(3), 314-328. https://doi.org/10.1017/jwe.2015.30

United State Association of Cider Makers. (2017). Strategic Plan 2017-2020.

Vermont Cider Classic. (2017). Vermont Cider Classic. Retrieved from http://www.vtciderclassic.com/

Vermont Ice Cider Association. (2017). Retrieved from http://www.vermonticecider.com/Vermont-Ice-Cider-Association.html

Watson, B. (2013). Cider, hard and sweet: history, traditions, and making your own (Third). Woodstock, Vermont: The Countryman Press.

Westons Cider. (2017). PGI Information. Retrieved from http://www.westons-cider.com/products/henry-westons/pgi-information/

Windfall Orchard. (2017). Farmhouse Hard Cider. Retrieved from http://windfallorchardvt.com/products/hard-cider/

\section{Notes}

Note 1: Ice cider is a fermented apple-based beverage closely related to hard cider.

\section{Copyrights}

Copyright for this article is retained by the author(s), with first publication rights granted to the journal.

This is an open-access article distributed under the terms and conditions of the Creative Commons Attribution license (http://creativecommons.org/licenses/by/4.0/). 